Virginia Commonwealth University

VCU Scholars Compass

2016

\title{
Development and Pilot of a Checklist for Management of Acute Liver Failure in the Intensive Care Unit
}

\author{
Oren K. Fix \\ Swedish Medical Center \\ Iris Liou \\ University of Washington \\ Constantine J. Karvellas \\ University of Alberta \\ See next page for additional authors
}

Follow this and additional works at: http://scholarscompass.vcu.edu/intmed_pubs

Part of the Medicine and Health Sciences Commons

(C) 2016 Fix et al. This is an open access article distributed under the terms of the Creative Commons Attribution License, which permits unrestricted use, distribution, and reproduction in any medium, provided the original author and source are credited.

\section{Downloaded from}

http://scholarscompass.vcu.edu/intmed_pubs/116

This Article is brought to you for free and open access by the Dept. of Internal Medicine at VCU Scholars Compass. It has been accepted for inclusion in Internal Medicine Publications by an authorized administrator of VCU Scholars Compass. For more information, please contact libcompass@vcu.edu. 
Authors

Oren K. Fix, Iris Liou, Constantine J. Karvellas, Daniel R. Ganger, Kinberly A. Forde, Ram M. Subramanian, Alice Boylan, James Hanje, R. Todd Stravitz, William M. Lee, and Acute Liver Failure Study Group 


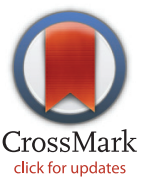

\section{G OPEnACCESS}

Citation: Fix OK, Liou I, Karvellas CJ, Ganger DR,

Forde KA, Subramanian RM, et al. (2016)

Development and Pilot of a Checklist for

Management of Acute Liver Failure in the Intensive

Care Unit. PLoS ONE 11(5): e0155500. doi:10.1371/

journal.pone.0155500

Editor: Tatsuo Kanda, Chiba University, Graduate School of Medicine, JAPAN

Received: February 28, 2016

Accepted: May 1, 2016

Published: May 13, 2016

Copyright: $\odot 2016$ Fix et al. This is an open access article distributed under the terms of the Creative Commons Attribution License, which permits unrestricted use, distribution, and reproduction in any medium, provided the original author and source are credited.

Data Availability Statement: All relevant data are within the paper and its Supporting Information files.

Funding: This work was supported by the National Institutes of Health/National Institute of Diabetes and Digestive and Kidney Diseases DK U-01-58369: WML (Principal Investigator), OKF, IL, CJK, DAG, KAF, RMS, AB, JH, RTS (Site Principal Investigators). The funders had no role in study design, data collection and analysis, decision to publish, or preparation of the manuscript.
RESEARCHARTICLE

\section{Development and Pilot of a Checklist for Management of Acute Liver Failure in the Intensive Care Unit}

\author{
Oren K. Fix ${ }^{1 *}$, Iris Liou ${ }^{2}$, Constantine J. Karvellas ${ }^{3}$, Daniel R. Ganger ${ }^{4}$, Kimberly A. Forde ${ }^{5}$, \\ Ram M. Subramanian ${ }^{6}$, Alice Boylan ${ }^{7}$, James Hanje ${ }^{8}$, R. Todd Stravitz ${ }^{9}$, William M. Lee ${ }^{10}$, \\ Acute Liver Failure Study Group
}

1 Swedish Medical Center, Organ Transplant Program, Seattle, Washington, United States of America, 2 University of Washington, Department of Medicine, Seattle, Washington, United States of America, 3 University of Alberta, Department of Medicine, Edmonton, Alberta, Canada, 4 Northwestern University, Department of Medicine, Chicago, Illinois, United States of America, 5 University of Pennsylvania, Department of Medicine, Philadelphia, Pennsylvania, United States of America, 6 Emory University, Department of Medicine, Atlanta, Georgia, United States of America, 7 Medical University of South Carolina, Department of Medicine, Charleston, South Carolina, United States of America, 8 The Ohio State University, Department of Medicine, Columbus, Ohio, United States of America, 9 Virginia Commonwealth University, Department of Medicine, Richmond, Virginia, United States of America, 10 University of Texas Southwestern, Department of Medicine, Dallas, Texas, United States of America

I) Membership of the Acute Liver Failure Study Group is listed in the Acknowledgments.

* oren.fix@swedish.org

\section{Abstract}

\section{Introduction}

Acute liver failure (ALF) is an ideal condition for use of a checklist. Our aims were to develop a checklist for the management of ALF in the intensive care unit (ICU) and assess the usability of the checklist among multiple providers.

\section{Methods}

The initial checklist was developed from published guidelines and expert opinion. The checklist underwent pilot testing at 11 academic liver transplant centers in the US and Canada. An anonymous, written survey was used to assess the usability and quality of the checklist. Written comments were used to improve the checklist following the pilot testing period.

\section{Results}

We received 81 surveys involving the management of 116 patients during the pilot testing period. The overall quality of the checklist was judged to be above average to excellent by $94 \%$ of users. On a 5-point Likert scale, the majority of survey respondents agreed or agreed strongly with the following checklist characteristics: the checklist was easy to read (99\% agreed/agreed strongly), easy to use (97\%), items are categorized logically (98\%), time to complete the checklist did not interfere with delivery of appropriate and safe patient care $(94 \%)$ and was not excessively burdensome (92\%), the checklist allowed the user the 
Competing Interests: The authors have declared that no competing interests exist. freedom to use his or her clinical judgment ( $80 \%)$, it is a useful tool in the management of acute liver failure (98\%). Web-based and mobile apps were developed for use of the checklist at the point of care.

\section{Conclusion}

The checklist for the management of ALF in the ICU was shown in this pilot study to be easy to use, helpful and accepted by a wide variety of practitioners at multiple sites in the US and Canada.

\section{Introduction}

\section{Acute liver failure management in the intensive care unit}

Acute liver failure (ALF) is caused by the sudden loss of liver function and defined by coagulopathy and encephalopathy in a patient without known pre-existing liver disease [1]. It is a complex medical condition involving critically ill patients with a high mortality, and requires an intensive care unit (ICU) setting and multidisciplinary team of providers to ensure the best possible outcome. The clinical course and complications from this syndrome are variable depending on the etiology of the liver failure, timing of presentation to medical care and inconsistent medical practices. ALF is a rare condition with an estimated incidence of 2,000 cases per year in the United States [2]. There are few controlled trials evaluating specific treatments for ALF. In spite of this, the management of ALF has advanced over the decades, best practices have evolved and outcomes have improved [3]. The advancement of electronic medical record systems and growing use of computerized physician order entry presents an opportunity for a standardized approach to optimize the management of ALF.

\section{Checklists in medicine}

Checklists are becoming more prevalent in medicine, particularly in the ICU. They have been shown to decrease medical errors, improve standards of patient care and improve adherence to best practices, particularly during complex tasks $[4,5]$. Well-known examples of checklists in medicine include the Catheter-Related Blood Stream Infection checklist developed at Johns Hopkins, which decreased the incidence of these infections from 11.3 to 0 per 1000 catheterdays [6]. The Surgical Safety Checklist, pioneered by Atul Gawande and the World Health Organization, reduced the risk of perioperative death from $1.5 \%$ to $0.8 \%$ and the risk of inpatient complications from $11 \%$ to $7 \%$ [7]. The success of these checklists derives in part from defined interventions and outcomes of interest.

We hypothesized that ALF is an ideal condition for use of a checklist because it requires a multidisciplinary team of providers to analyze and manage a highly complex condition in a demanding and stressful ICU setting. Our aims were to develop a checklist for the management of ALF in the ICU and assess the usability of the checklist among multiple types of providers in order to standardize and improve management of ALF in the ICU.

\section{Methods}

The initial checklist was developed from December 2010 to March 2012. We used published guidelines $[8,9]$ and expert opinion (selected principal investigators in the Acute Liver Failure Study Group), recognizing that few randomized controlled trials exist to guide management of 
ALF. Items with insufficient or controversial data were included when there was consensus that the recommendation was beneficial. Initial drafts were reviewed by the experts and refined iteratively through consensus.

The checklist underwent pilot testing from May 2012 to April 2013 at 11 academic liver transplant centers in the US and Canada (Table 1). Each site was led by an experienced transplant hepatologist. Five sites were not originally among the ALFSG network, of which 4 sites later joined the group. Three of these 4 new sites had investigators who were dual-certified in both transplant hepatology and critical care. We developed an online instructional video (http://alfchecklist.com/video) to demonstrate how to use the checklist.

An anonymous, written survey form was used to assess the usability and quality of the checklist (Fig 1). Health care providers were the research subjects. The study was explained to the provider and an information sheet was provided. Verbal consent was obtained and documentation of consent was assumed by the research subject's completion of the survey. We surveyed multiple checklist users per patient but only a single survey was administered to each research subject for the duration of the pilot study. Written comments were used to improve the checklist following the pilot testing period.

Institutional review boards at each of the following sites approved the study: University of California, San Francisco, California, USA; University of Texas Southwestern, Dallas, Texas, USA; Medical University of South Carolina, Charleston, South Carolina, USA; Northwestern University, Chicago, Illinois, USA; University of Washington, Seattle, Washington, USA; University of Pennsylvania, Philadelphia, Pennsylvania, USA; University of Colorado, Denver, Colorado, USA; Yale University, New Haven, Connecticut, USA; University of Alberta, Edmonton, Alberta, Canada (Research Ethics Board); The Ohio State University, Columbus, Ohio, USA; Emory University, Atlanta, Georgia, USA.

\section{Results}

\section{Initial checklist design}

The initial checklist design included 3 distinct sections on 2 pages. The checklist was also separated into sections to be reviewed on admission to the ICU and on a daily basis. The first section contained a list of best practices recommended for every ALF patient in the ICU. Recognizing that etiology is the most important determinant of prognosis, the first page contained a table of etiologies, followed by items that should be completed to identify the cause of ALF. Some of these items were recommended for every ALF patient admitted to the ICU regardless of the presumed etiology. The second page was organized by organ system, containing questions for each system designed to prompt action according to the patient's status.

Table 1. Checklist pilot sites.

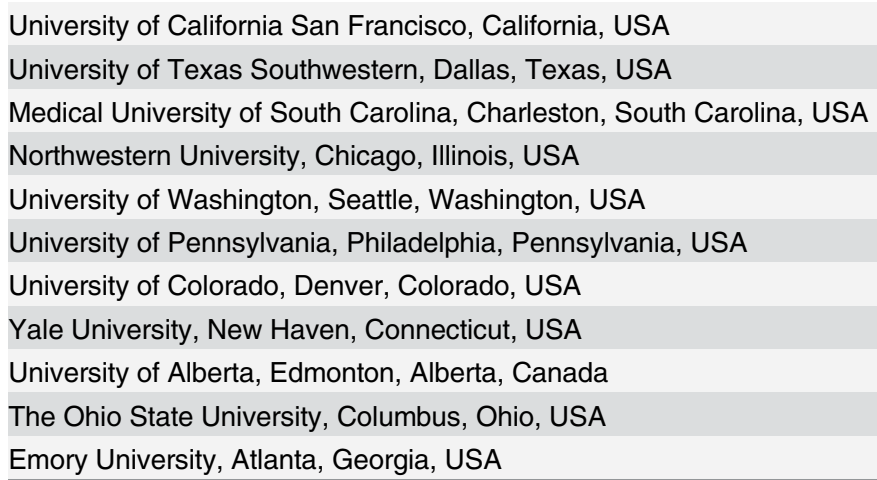

doi:10.1371/journal.pone.0155500.t001 


\section{ACUTE LIVER FAILURE (ALF) CHECKLIST SURVEY}

I am a:

$\square \quad$ Nurse

$\square \quad$ Internal Medicine resident

$\square$ Surgery resident

$\square \quad$ GI fellow

$\square \quad$ Hepatology fellow

$\square \quad$ Critical care fellow

$\square \quad$ Critical care attending

$\square \quad$ Hepatology attending

$\square \quad$ Surgery attending

$\square$ Other, please specify:
I used the checklist:

Yes

No

(You may still comment on your reasons why not below)

\section{Disagree} strongly

The checklist was easy to read

The checklist was easy to use

The items on the checklists are categorized logically

The time to complete the checklist did not interfere with delivery of appropriate and safe patient care

The time to complete the checklist was not excessively burdensome

The checklist allowed me the freedom to use my clinical judgment

The checklist is a useful tool in the management of ALF

If I were a patient with ALF, I would want the checklist to be used

How can we improve the checklist? (Feel free to use the back if you need more room)

Fig 1. Checklist pilot survey.

doi:10.1371/journal.pone.0155500.g001 


\section{Pilot testing}

We received 81 surveys from the 11 pilot sites (Table 1) involving the management of 116 ALF patients during the pilot testing period. A variety of different users completed the surveys, including physicians and non-physicians, faculty and trainees (Table 2). Among checklist users surveyed, 99\% agreed or agreed strongly that the checklist was easy to read, $97 \%$ agreed or agreed strongly that it was easy to use, $98 \%$ agreed that the items on the checklist are categorized logically, $94 \%$ agreed that the time to complete the checklist did not interfere with delivery of appropriate and safe patient care, $92 \%$ agreed that the time to complete the checklist was not excessively burdensome. $80 \%$ agreed or agreed strongly that the checklist allowed the user the freedom to use his or her clinical judgment, $98 \%$ agreed the checklist is a useful tool in the management of ALF, and 99\% agreed or agreed strongly that they would want the checklist to be used if they were a patient with ALF (Fig 2). All checklist users stated they would use the checklist again at the time of admission and $85 \%$ would use it on a daily basis. The overall quality of the checklist was judged to be above average to excellent by $94 \%$ of users.

Subgroup analysis of the item that received the lowest rating (80\% agreed or agreed strongly that the checklist allowed the user the freedom to use his or her clinical judgment) showed that non-physicians were more likely than physicians to disagree or respond neutrally that the checklist allowed for clinical judgment (29\% vs. $18 \%$ ), while more senior staff physicians disagreed with this statement compared to trainees (30\% vs $16 \%$ ).

Data obtained from pilot testing, including quantitative feedback and written comments, were used to revise the checklist (Table 3). The final checklist is shown in Fig 3.

\section{Discussion}

Management of ALF in the ICU is not an exact science, with disparate practices at each center even within the cohesive and long-standing network of centers comprising the Acute Liver Failure Study Group. The lack of randomized controlled trials and established clinical endpoints, other than transplant-free survival, further complicates progress toward a standardized approach. Therefore, a checklist for the management of ALF in the ICU would seem an

Table 2. Checklist users.

\begin{tabular}{lll}
\hline Staff Physicians & & $\mathbf{1 9}$ \\
\hline & Critical care & 15 \\
\hline Trainees & Hepatology & 4 \\
& & 48 \\
& Gastroenterology fellow & 10 \\
& Critical care fellow & 4 \\
& Hepatology fellow & 7 \\
& Transplant surgery fellow & 1 \\
\hline & Internal medicine resident & 21 \\
& Surgery resident & 2 \\
& Emergency resident & 1 \\
& Anesthesia resident & 1 \\
\hline Other & Medical student (4 ${ }^{\text {th }}$ year) & 1 \\
\hline & & 14 \\
\hline
\end{tabular}

doi:10.1371/journal.pone.0155500.t002 


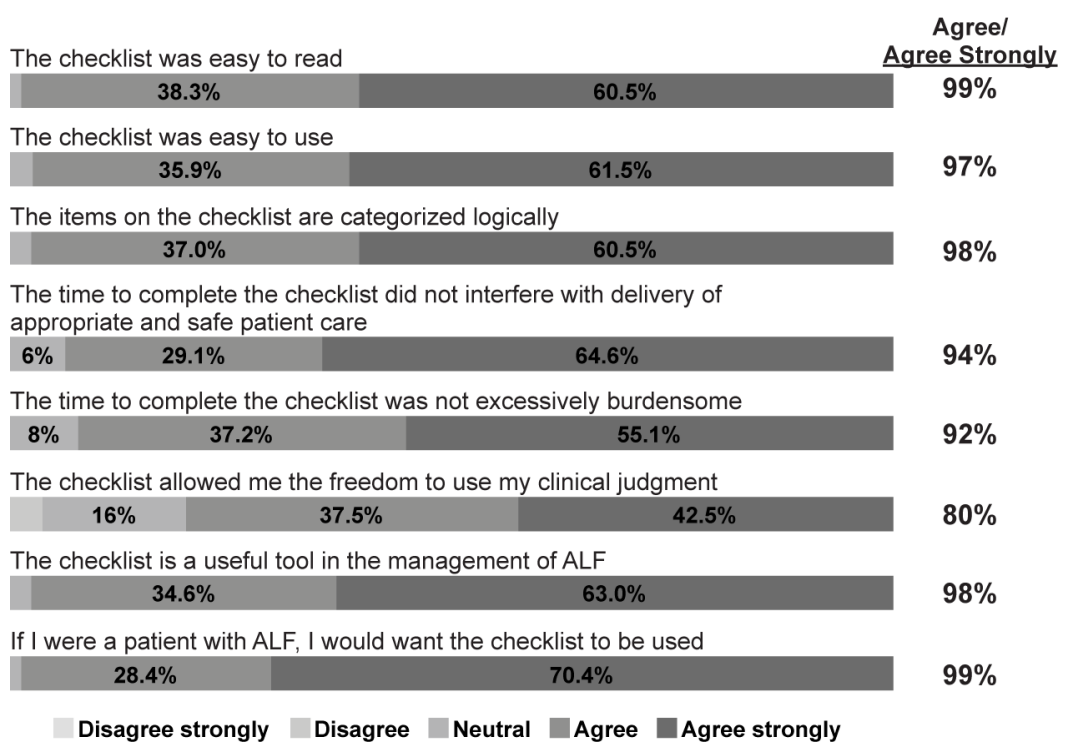

Fig 2. Pilot survey results.

doi:10.1371/journal.pone.0155500.g002

appropriate step to provide a synthesis of expert opinion, consensus and iteration guided by both quantitative and qualitative feedback through pilot testing.

Our pilot testing revealed that the preliminary checklist was a helpful tool for the management of ALF in the ICU, and was considered to be organized logically and easy to use. The vast majority of surveyed users found the checklist to be above average to excellent on a 5-point Likert scale, would use the checklist on a daily basis for future ALF patients and would want the checklist to be used if they themselves were a patient with ALF.

One of the goals of the checklist is to standardize and optimize ICU care for this rare syndrome. Given the highly complex management required by these critically ill patients who often experience rapid fluctuations in clinical status, this checklist can serve as a useful tool and a reminder of recommended practices. The checklist recommendations can be easily translated to physician order sets adapted to local institutional practices.

There are limitations to using checklists in medicine. Overuse of checklists can overburden clinicians, unnecessarily complicate tasks, increase complexity and reduce efficiency [5]. Some of the survey items we included were meant to explore whether our checklist suffered from these limitations, but we found high levels of agreement indicating the checklist did not

Table 3. Examples of changes made to the checklist as a result of pilot testing.

Increased mean arterial pressure goal from 65 to $75 \mathrm{~mm} \mathrm{Hg}$ for patients with encephalopathy grade III/IV Clearly differentiated prophylaxis of intracranial hypertension from treatment

Specified that hypertonic saline should be used for prophylaxis of intracranial hypertension rather than treatment

Removed specific references to concentration and mode of delivery of hypertonic saline in order to acknowledge different practices across centers

More clearly stated the preference for continuous renal replacement therapy over intermittent hemodialysis when initiating renal replacement therapy

Separated "clinically significant bleeding" from "planned invasive procedure" to avoid promoting unnecessary correction of the international normalized ratio for invasive procedures Increased the glucose upper limit from 150 to $180 \mathrm{mg} / \mathrm{dL}$

doi:10.1371/journal.pone.0155500.t003 
DO NOT PLACE IN THE MEDICAL RECORD ADMISSION AND DIAGNOSIS ALF CHECKLIST

THE FOLLOWING ARE TO BE DONE ON ADMISSION AND DAILY IN ALL CASES OF ALF:

a Neuro checks every 1-2 hours

Head of the bed at $30^{\circ}$

Head in neutral position

Minimize stimulation (tracheal suctioning, chest physiotherapy, sternal rubbing)

$\mathrm{N}$-acetylcysteine (NAC) IV until INR $<1.5$ or resolution of encephalopathy ${ }^{\star}$

CXR and surveillance cultures (blood, urine, sputum) on admission and every 24-48 hrs

Monitor blood glucose every 1-2 hours

Avoid nephrotoxic drugs (aminoglycosides, NSAIDs, neomycin, etc) and IV contrast

DVT prophylaxis (sequential compression device) despite coagulopathy; avoid heparin

PPI for stress ulcer prophylaxis

Communication: 1) intensivist and/or transplant hepatologist, 2) nurse, 3) patient's family

\begin{tabular}{|c|c|c|c|c|}
\hline $\begin{array}{l}\text { POSSIBLE } \\
\text { ETIOLOGY }\end{array}$ & & $\begin{array}{l}\text { DIAGNOSTIC ITEMS TO DO IN } \\
\text { ALL CASES OF ALF }\end{array}$ & $\begin{array}{l}\text { DIAGNOSTIC ITEMS } \\
\text { TO CONSIDER }\end{array}$ & SPECIFIC THERAPIES \\
\hline Drug/toxin & व & $\begin{array}{l}\text { Obtain 6-month } \\
\text { medication/toxin/ingestion } \\
\text { history including OTC } \\
\text { supplements, herbals, wild } \\
\text { mushrooms, weight loss drugs } \\
\text { Urine and serum toxicology } \\
\text { screens } \\
\text { Acetaminophen level }\end{array}$ & & $\begin{array}{l}\text { Acetaminophen toxicity: } \\
\text { NAC } \\
\text { Mushroom poisoning: } \\
\text { Charcoal, NAC, penicillin } \\
\text { G and/or silibinin }\end{array}$ \\
\hline Viral & & $\begin{array}{l}\text { Anti-HAV IgM } \\
\text { HBsAg, anti-HBc IgM, } \\
\text { HBV DNA (quantitative) } \\
\text { Anti-HCV, HCV RNA }\end{array}$ & $\begin{array}{l}\text { Anti-HEV } \\
\text { HSV DNA } \\
\text { EBV DNA } \\
\text { CMV DNA } \\
\text { Anti-HDV/HDV RNA }\end{array}$ & $\begin{array}{l}\text { HBV: Entecavir } \\
\text { HSV: Acyclovir }\end{array}$ \\
\hline Autoimmune & $\begin{array}{l}\square \\
\square\end{array}$ & $\begin{array}{l}\text { Antinuclear antibody } \\
\text { Anti-smooth muscle } \\
\text { antibody/anti-actin antibody } \\
\text { Immunoglobulin G }\end{array}$ & $\begin{array}{l}\text { Anti-liver/kidney microsomal } \\
\text { antibody } \\
\text { Liver biopsy }\end{array}$ & Corticosteroids \\
\hline $\begin{array}{l}\text { Vascular } \\
\text { Budd Chiari } \\
\text { Ischemia }\end{array}$ & ם & $\begin{array}{l}\text { Abdominal ultrasound with } \\
\text { Doppler }\end{array}$ & $\begin{array}{l}\text { CT/MRI } \\
\text { Assess for hypercoagulable } \\
\text { state including search for } \\
\text { malignancy } \\
\text { Interventional radiology } \\
\text { consultation } \\
\text { Echocardiography/ECG }\end{array}$ & $\begin{array}{l}\text { Budd Chiari: } \\
\text { Anticoagulation, TIPS }\end{array}$ \\
\hline Wilson & ם & $\begin{array}{l}\text { Check for hemolytic anemia } \\
\text { (high indirect bilirubin), low } \\
\text { alkaline phosphatase, renal } \\
\text { failure, acidosis }\end{array}$ & $\begin{array}{l}\text { Ceruloplasmin } \\
\text { 24-hour urine for copper } \\
\text { Serum copper } \\
\text { Ophthalmology consultation to } \\
\text { look for Kayser-Fleischer rings }\end{array}$ & Consider early CRRT \\
\hline AFLP / HELLP & & & $\begin{array}{l}\beta-H C G \\
\text { Obstetrics consultation }\end{array}$ & Early delivery \\
\hline Malignancy & & & $\begin{array}{l}\text { CT/MRI } \\
\text { Liver biopsy }\end{array}$ & \\
\hline Indeterminate & & & Liver biopsy & \\
\hline \multicolumn{5}{|c|}{ 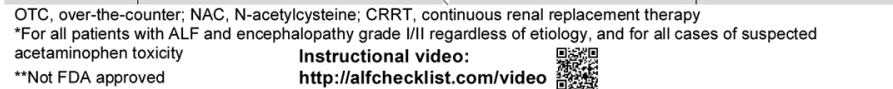 } \\
\hline
\end{tabular}

DO NOT PLACE IN THE MEDICAL RECORD ADMISSION AND DAILY ALF CHECKLIST

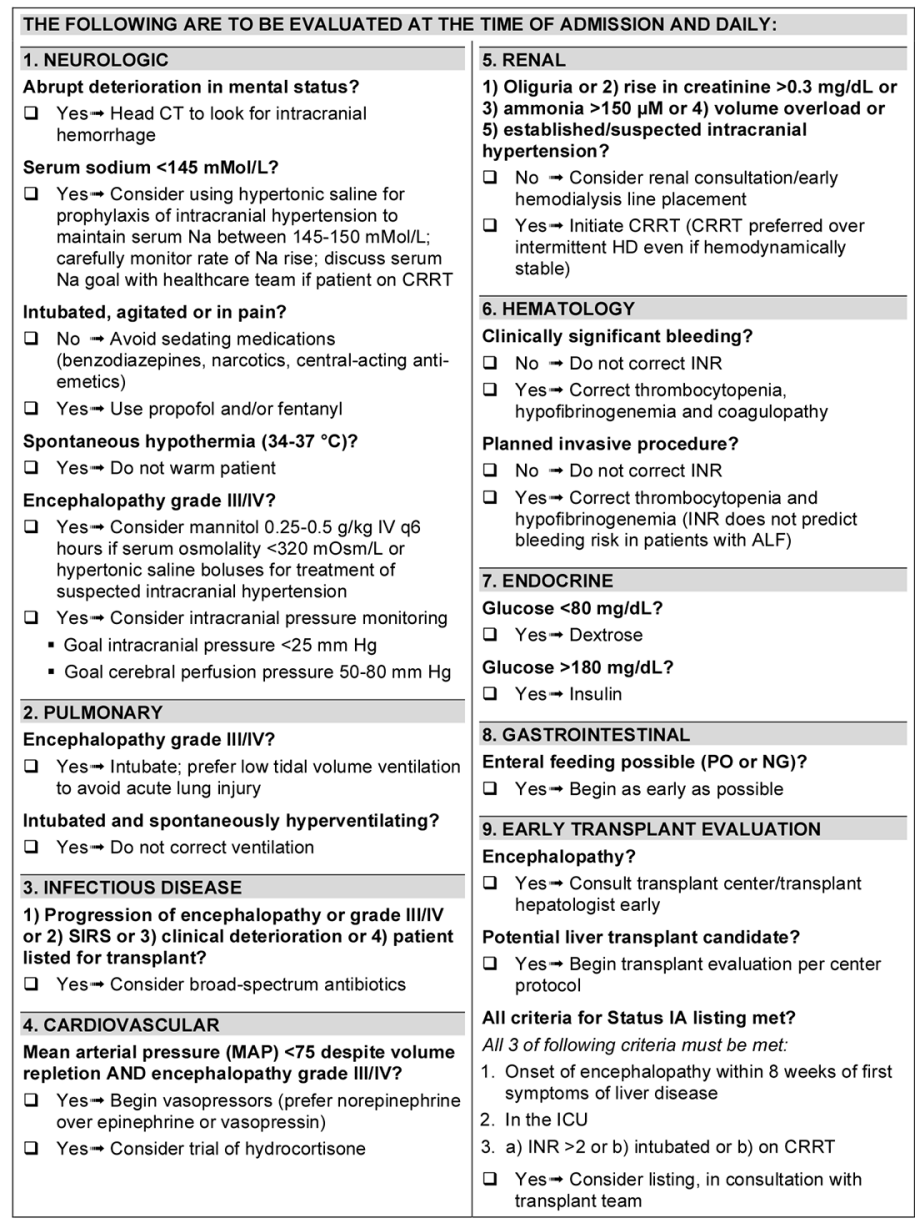

NAC, N-acetylcysteine; CRRT continuous renal replacement therapy

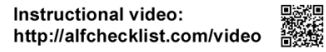

\section{Fig 3. Final checklist.}

interfere with delivery of appropriate and safe patient care, was not excessively burdensome and generally allowed providers the freedom to use their clinical judgment.

Five respondents specifically commented that the checklist is not sufficiently instructive and that the reasons for some recommendations are not elaborated (e.g., "Better rationale regarding explanations of course of actions", "Include a section on managing metabolic acidosis", "Define grade III/IV encephalopathy"). We designed the checklist, not as a teaching tool, but rather as a reminder of critical management steps. The ideal checklist user is the experienced provider who is comfortable with the management of ALF in the ICU rather than the novice who is seeking an algorithmic approach. In a limited way, however, some users, particularly trainees, found the checklist to be useful as an educational resource.

Another criticism of the checklist was that some recommendations do not correspond with institution-specific practices (e.g., "I would like to see the checklist be more center specific", "Extensive mention of intracranial pressure monitoring, which I haven't seen used often"). One of our aims was to standardize the management of ALF across centers. While we 
attempted as best as possible to create a checklist that was generalizable and respected institution-specific nuances, we recognized that it is impractical to design a checklist that incorporates all such practices.

The item on the survey that received the lowest rating of $80 \%$ (the checklist allowed the user the freedom to use his or her clinical judgment)-still a very favorable rating-suggested qualitatively that some users felt the checklist did in some ways interfere with freedom to use clinical judgment. Based on written comments, one reason for the lower ratings for this item was due to the table of etiologies on the first page of the checklist. In this table, the checklist directs the user to order a number of tests regardless of possible etiology, which includes checking viral and autoimmune serologies. Some users criticized this recommendation as being unnecessary when the diagnosis is known, for example in some cases of acetaminophen overdose (e.g., "No need for all labs in cases where acetaminophen overdose clear", "An autoimmune panel may not be necessary in a case of clear acetaminophen toxicity"). After discussing this issue among the experts, we chose to leave this as a recommended part of the management of a patient with ALF, recognizing how common some of these etiologies are and the possibility for multiple etiologies to exist simultaneously and perhaps influence prognosis. As one of our goals was to standardize and improve management of ALF based on published guidelines and expert opinion, some restriction in the freedom to deviate from the checklist may be considered a desirable feature.

All checklist users were willing to use the checklist at the time of admission and a high proportion reported they would use it on a daily basis. The checklist may be more critical at the time of admission when an initial management plan is formulated and the majority of orders are written; however, the daily assessment is still crucial to the management of ALF patients who often progress rapidly. Promoting use of a point-of-care tool such as a Web-based or mobile app may simplify the daily assessment and encourage more frequent use of the checklist.

\section{Point-of-care apps}

Web-based and mobile apps were developed to facilitate future use of the finalized version of the checklist at the point of care. The Web-based app, which is optimized for use with mobile devices, contains tooltips to explain some of the checklist items and also contains links to additional resources and background information for the management recommendations. The Web-based application can be found at http://alfchecklist.com and the iOS mobile app is available on the Apple ${ }^{\circledR}$ App Store.

\section{Future directions}

We plan to revise this checklist as new data and best practices on the management of ALF in the ICU emerge. Extension of use of this checklist to non-university-based liver transplant centers and community hospitals without liver transplant services could be explored to broaden its utility. Creating a condensed version of the checklist for the emergency department setting is another option to expand its function. The clinical impact of the checklist was not evaluated in this study; therefore, it will be important to assess use of the checklist on clinically relevant outcomes in a future study.

\section{Conclusion}

The Acute Liver Failure Study Group checklist for the management of acute liver failure in the intensive care unit was shown in this pilot study to be easy to use, helpful and accepted by a 
wide variety of practitioners at multiple sites in the US and Canada. Future studies will need to determine the impact of the checklist on management of acute liver failure.

\section{Supporting Information}

\section{S1 File. Minimal Data Set.}

(XLSX)

\section{Acknowledgments}

The Lead author/ Principal investigator of the Acute Liver Failure Study Group is Dr. William M. Lee (Division of Digestive Diseases, University of Texas Southwestern; email: william. lee@utsouthwestern.edu).Current/previous principal co-investigators and institutions participating in the Acute Liver Failure Study Group are as follows:

- Anne M. Larson, MD, Division of Digestive and Liver Diseases, University of Texas Southwestern, Dallas, Texas, United States of America

- Iris Liou, MD, Division of Gastroenterology, University of Washington, Seattle, Washington, United States of America

- Timothy Davern, MD, Center for Liver Disease, California Pacific Medical Center, San Francisco, California, United States of America

- Oren K. Fix, MD, Organ Transplant Program, Swedish Medical Center, Seattle, Washington, United States of America

- Michael Schilsky, MD, Division of Digestive Diseases/Transplant: Yale University, New Haven, Connecticut, United States of America

- Timothy McCashland, MD, Division of Gastroenterology-Hepatology, University of Nebraska, Omaha, Nebraska, United States of America

- J. Eileen Hay, MBBS, Department of Gastroenterology and Hepatology, Mayo Clinic, Rochester, Minnesota, United States of America

- Natalie Murray, MD, Section of Gastroenterology and Hepatology, Baylor University Medical Center, Dallas, Texas, United States of America

- Obaid S. Shaikh, MD, Division of Gastroenterology, Hepatology and Nutrition, University of Pittsburgh, Pittsburgh, Pennsylvania, United States of America

- Andres Blei, MD, Division of Gastroenterology and Hepatology, Northwestern University, Chicago, Illinois, United States of America (deceased)

- Daniel Ganger, MD, Division of Gastroenterology and Hepatology, Northwestern University, Chicago, Illinois, United States of America

- Atif Zaman, MD, Division of Gastroenterology and Hepatology, Oregon Health and Sciences University, Portland, Oregon, United States of America

- Steven H.B. Han, MD, Division of Digestive Diseases, University of California, Los Angeles, California, United States of America

- Robert Fontana, MD, Division of Gastroenterology, University of Michigan, Ann Arbor, Michigan, United States of America 
- Brendan McGuire, MD, Division of Gastroenterology and Hepatology, University of Alabama, Birmingham, Alabama, United States of AmericaRaymond T. Chung, MD, Division of Gastroenterology, Massachusetts General Hospital, Boston, Massachusetts, United States of America

- Alastair Smith, MB, ChB, Division of Gastroenterology, Duke University Medical Center, Durham, North Carolina, United States of America

- Robert Brown, MD, Division of Digestive and Liver Diseases, Cornell/Columbia University, New York, New York, United States of America

- Jeffrey Crippin, MD, Division of Gastroenterology, Washington University, St Louis, Missouri, United States of America

- Edwin Harrison, MD, Division of Gastroenterology and Hepatology, Mayo Clinic, Scottsdale, Arizona, United States of America

- Adrian Reuben, MBBS, Division of Gastroenterology and Hepatology, Medical University of South Carolina, Charleston, South Carolina, United States of America

- Santiago Munoz, MD, Division of Gastroenterology and Liver Diseases, Albert Einstein Medical Center, Philadelphia, Pennsylvania, United States of America

- Rajender Reddy, MD, Division of Gastroenterology, University of Pennsylvania, Philadelphia, Pennsylvania, United States of America

- R. Todd Stravitz, MD, Division of Gastroenterology, Hepatology and Nutrition, Virginia Commonwealth University, Richmond, Virginia, United States of America

- Lorenzo Rossaro, MD, Division of Gastroenterology and Hepatology, University of California Davis, Sacramento, California, United States of America

- Raj Satyanarayana, MD, Division of Gastroenterology and Hepatology, Mayo Clinic, Jacksonville, Florida, United States of America

- Tarek Hassanein, MD, Division of Gastroenterology, University of California, San Diego, California, United States of America

- James Hanje, MD, Division of Gastroenterology, Hepatology and Nutrition, Ohio State University, Columbus, Ohio, United States of America

- Jody Olson, MD, Division of Gastroenterology, Hepatology and Motility, University of Kansas, Kansas City, Kansas, United States of America

- Ram Subramanian, MD, Division of Digestive Diseases, Emory, Atlanta, Georgia, United States of America

- Constantine J. Karvellas, MD, Division of Gastroenterology, University of Alberta, Edmonton, Canada

- The University of Texas Southwestern Administrative Group included Grace Samuel, Ezmina Lalani, Carla Pezzia, Corron Sanders, PhD, Nahid Attar, Linda S. Hynan, PhD.

- The Medical University of South Carolina Data Coordination Unit included Valerie Durkalski, PhD, Wenle Zhao, PhD, Jaime Speiser, Catherine Dillon, Holly Battenhouse and Michelle Gottfried. 


\section{Author Contributions}

Conceived and designed the experiments: OKF IL WML. Performed the experiments: OKF IL CJK DAG KAF RMS AB JH RTS WML. Analyzed the data: OKF IL CJK. Wrote the paper:

OKF IL.

\section{References}

1. Trey C, Davidson CS. The management of fulminant hepatic failure. Prog Liver Dis 1970; 3:282-98. PMID: 4908702

2. Lee WM. Acute liver failure in the United States. Semin Liver Dis 2003; 23:217-26. PMID: 14523675

3. Bernal W, Hyyrylainen A, Gera A, Audimoolam VK, McPhail MJ, Auzinger G, et al. Lessons from lookback in acute liver failure? A single centre experience of 3300 patients. J Hepatol 2013; 59:74-80. doi: 10.1016/j.jhep.2013.02.010 PMID: 23439263

4. Hales B, Terblanche M, Fowler R, Sibbald W. Development of medical checklists for improved quality of patient care. Int J Qual Health Care 2008; 20:22-30. PMID: 18073269

5. Winters BD, Gurses AP, Lehmann H, Sexton JB, Rampersad CJ, Pronovost PJ. Clinical review: checklists—translating evidence into practice. Crit Care 2009; 13:210.

6. Berenholtz SM, Pronovost PJ, Lipsett PA, Hobson D, Earsing K, Farley JE, et al. Eliminating catheterrelated bloodstream infections in the intensive care unit. Crit Care Med 2004; 32:2014-20. PMID: 15483409

7. Haynes AB, Weiser TG, Berry WR, Lipsitz SR, Breizat AH, Dellinger EP, et al. A surgical safety checklist to reduce morbidity and mortality in a global population. N Engl J Med 2009; 360:491-9. doi: 10. 1056/NEJMsa0810119 PMID: 19144931

8. Stravitz RT, Kramer AH, Davern T, Shaikh AO, Caldwell SH, Mehta RL, et al. Intensive care of patients with acute liver failure: recommendations of the U.S. Acute Liver Failure Study Group. Crit Care Med 2007; 35:2498-508. PMID: 17901832

9. Bernal W, Auzinger G, Sizer E, Wendon J. Intensive care management of acute liver failure. Semin Liver Dis 2008; 28:188-200. doi: 10.1055/s-2008-1073118 PMID: 18452118 